Education \& Training | Alice Letvin \& Carolyn Saper

\title{
How joyful dialogic reading jumpstarts early learning
}

The role of family engagement in children's early learning is crucial to their future educational prospects. Alice Letvin and Carolyn Chice who are based in ReadAskChat dialogic reading app for families with babies toddlers, and prereaders. The ReadAskChat app includes a library of short, content-rich stories and prompts for adult readers to stimulate brainbuilding "serve-and-return"
conversations. Complementing the app ar Re Complementing programs of adult learning in programs of adult learning in that has been shown to foster reading and school readiness and social-emotional growth.

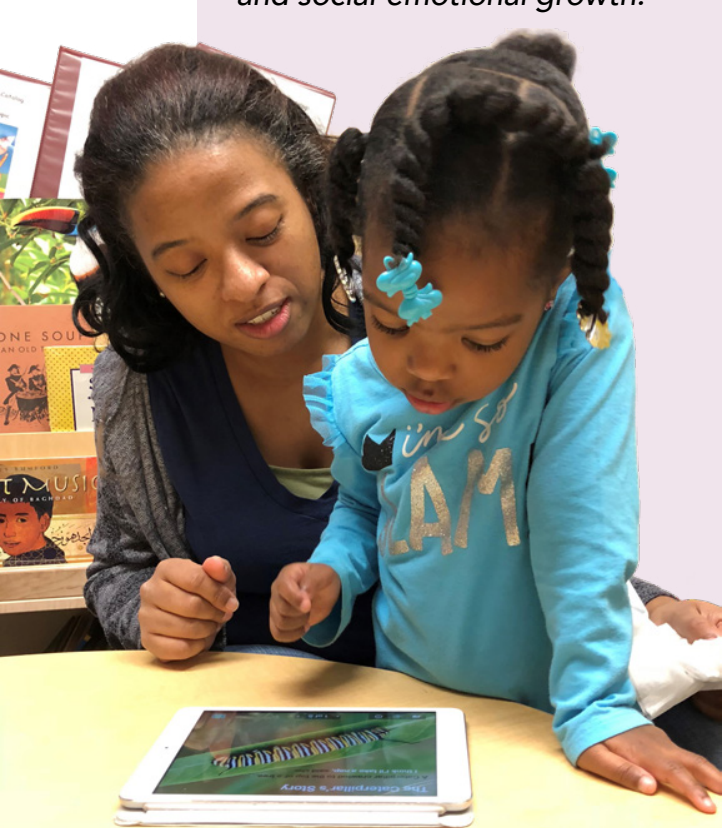

he seminal fact that inspired and guided the design of ReadAskChat is that 90 percent during the first five years of life--before policymakers increasingly understand the long-term impacts of early education on children's future schoo and life trajectories. During this critical developmental window, pare their child's first teacher. ReadAskChat offers an enjoyable, research-based method and digital tool to empower families to advance their young children's cognitive and social-emotio development.

The ReadAskChat tool is a picture-book quality library app that includes ondemand guidance in dialogic reading practices for parents, caregivers, and six months up to ages 6/7 years. Each story in the library was chosen to sustain brain-building back-and-forth conversations, shared storytelling, and engagement with concepts and ideas With its particular focus on reading for meaning, ReadAskChat aims to cultiv habits of mind that lead to motivated, independent reading. Complementing the library app are the ReadAskCha programs of online adult learning in dialogic reading, suitable for a variety of audiences, including preservice teachers, early childhood teachers and

Multiple investments by the U.S. Alice Letvin, PhD, and Carolyn
Saper, MST, to develop and launch ReadAskChat.

\section{READASKCHAT - RESEARCH BASE} The ReadAskChat design is based on esearch from many fields - from brain science to learning theory to human sciology of ducation. Its core objective is to guide and encourage families to talking about stories from the earliest age. This process - called dialogic reading by the American Academy of Paediatrics - has been shown to foster virtually all school-readiness indicators, including vocabulary and knowledge attainment, concepts about print, executive functioning, and sociaemotional learning

Unlike most other education products ome, ReadAskChat is developmental, and is based on a young children learn best including the fact that very young children only earn language from other humans, not from digital media or recordings. ReadAskChat places the development of early literacy and language on equal footing with creative thinking and open-ended questioning. Research also shows that science learning, which can be promoted through exposure to science topics and dialogic reading, should be cultivated before kindergarten entry, so children begin school with age-appropriate content and conceptua wondedge anperime capacity to observe, Profound inequities in children's

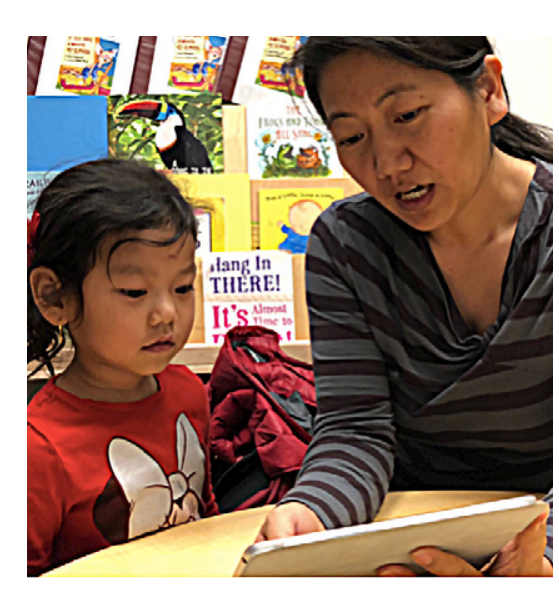

social-emotional development.

educational experiences, achievement, and opportunities persist, even in developed countries like the U.S and U.K. Too many children start school below grade level norms, and the majority of those children end schooling. But an influential 2018 Technology found that family language that includes "conversational turns" of the kind fostered by ReadAskChat accounted for significant differences in brain physiology and increases in language skills among children exposed to such conversations. These findings are particularly encouraging because they pertained to children regardless of parental income or education.

AN INNOVATION IN DIALOGIC READING AND DARENTEMPOWERMENT edAskChat conforms to a cuttingedge understanding of family experienced by most fan iles tossures think of "engagement" as how often parents attend school meetings is needlessly limited. Rather, ReadAskChat embraces the more expan of engagement as the degree to which in their children's educational success. The easily accessible digital library, the dialogic reading method-Read Read Again, Ask \& Chat-and textspecific conversation starters make such engagement possible. This seamless learning scaffolding for adults is feasible only through a digital medium.

A sequence of on-demand dialogic reading prompts at three developn
levels-Babies, Toddlers, and turns with the dr chld, naming who is
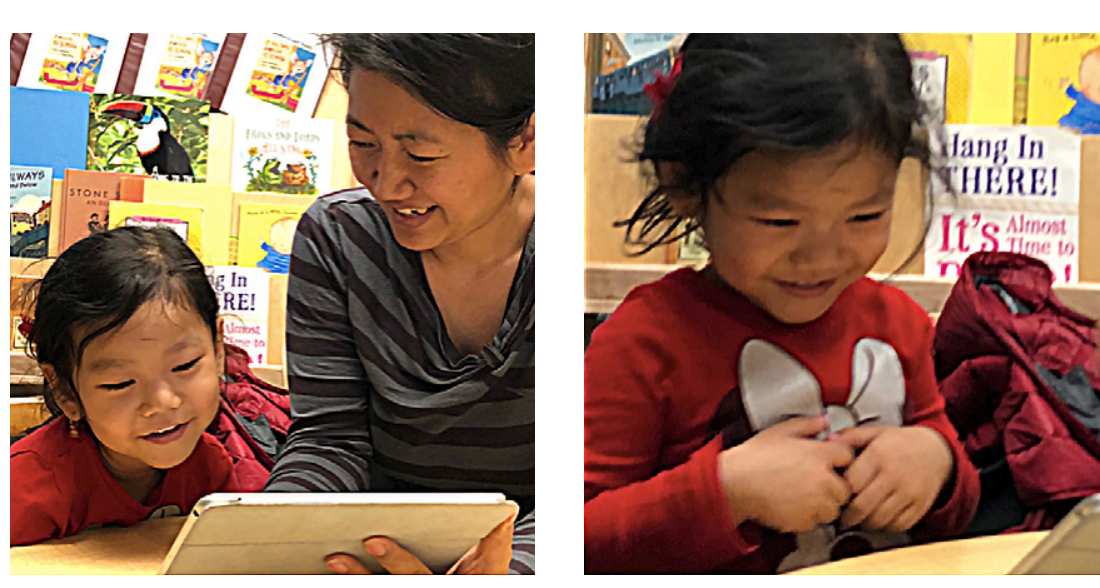

Prereaders-are embedded on each page of the library. All prompts are based on this developmental continuum. With babies, adults are guided to model. Whins widhers, adults are guided to take With older, prereading children, prompts suggest ways for child and adult to build ideas and excitement about stories through playful and imaginative back-and-forth conversations. These graduated prompts enable parents to experience. Through talk with a caring

adult, children gradually internalise language and meaning, and mo mature thinking develops.

ReadAskChat is not a babysitting app. Unlik most education apps in today's versions of worksheets, games, and (azzer and children together to construct meaning collaboratively and bond with each other. Each ReadAskChat story also includes suggestions for extending children's learning beyond the reading experience through related creative

By encouraging reading for meaning, ReadAskChat helps to develop motivated, independent reading, while promoting knowledge and vocabulary building, and family bonding.

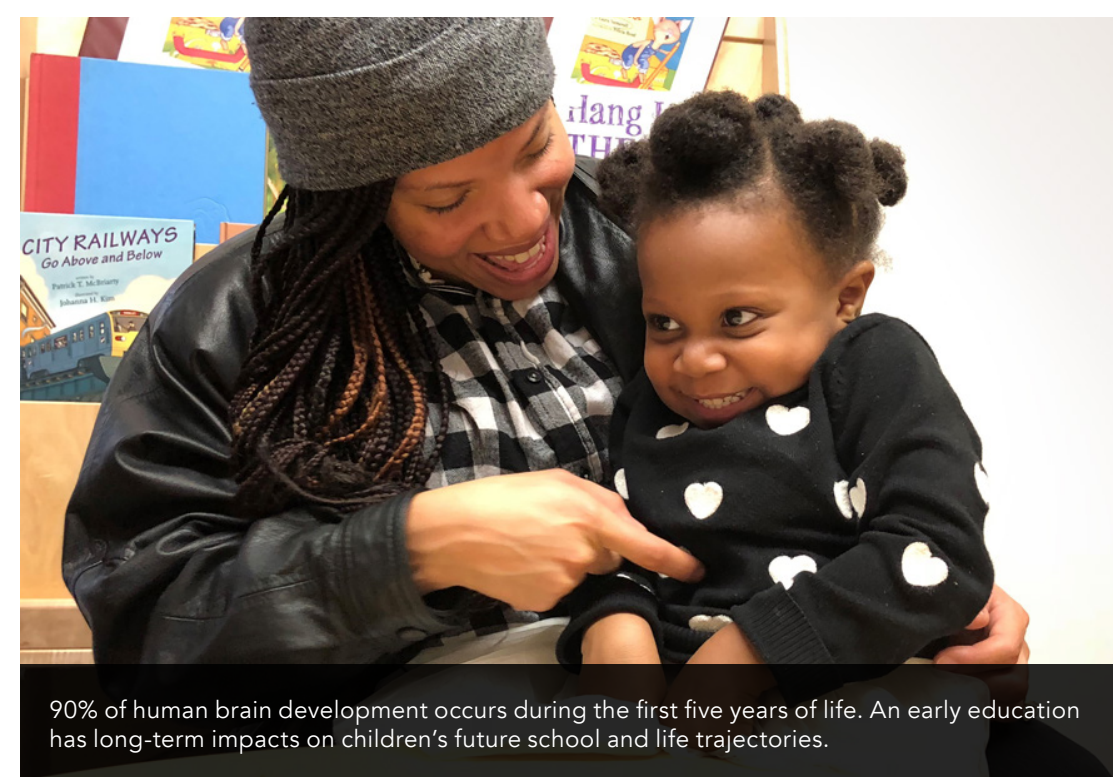


play, drawing, playacting, storytelling and real-world explorations. The inherently meaningful and activities ase foundation for open communication that can last throughout childhood and youth.

For all these reasons, ReadAskChat is a learning tool for adults as much as for children. Conversation starters serve as a personal coach, to be used as needed. The expectation is that over time, adults will internalise the dialogic reading process, while children will apply an active, collaborative learning approach to other educational settings. To further adults' understanding and facility in joyful dialogic reading, ReadAskChat is producing series of 36 brief video tutorials (avalable late 2020/early 2021) and open-ended, nondidactic questioning and conversation.

Research evidence suggests that goal setting and regular "nudges" can increase parent participation in various simple reminders can have an outsized

impact. To help establish a routine of at-home reading, parents set their Supportive or celebratoy notifications based on the progress or completion of the goals each family sets for itself are then sent by ReadAskChat each week.

Organisations integrating ReadAskChat into their initiatives supporting children and families can track engagement data through multiple metrics on the individual level and in aggregate. Metrics include number of stories read; time spent reading; favourite stories; reading goals met; and conversatio

\section{FUTURE DIRECTIONS}

The positive experience of parents using ReadAskChat suggests that it development tool for classroom teachers and assistant teachers could also be used to advance shared storytelling among young children in group settings. Shared storytelling has been shown to develop vocabulary and language skills and deepen literal and inferential comprehension.

The positive experience of parents with ReadAskChat suggests that it could become a powerful professional development tool for classroom teachers and assistant teachers.

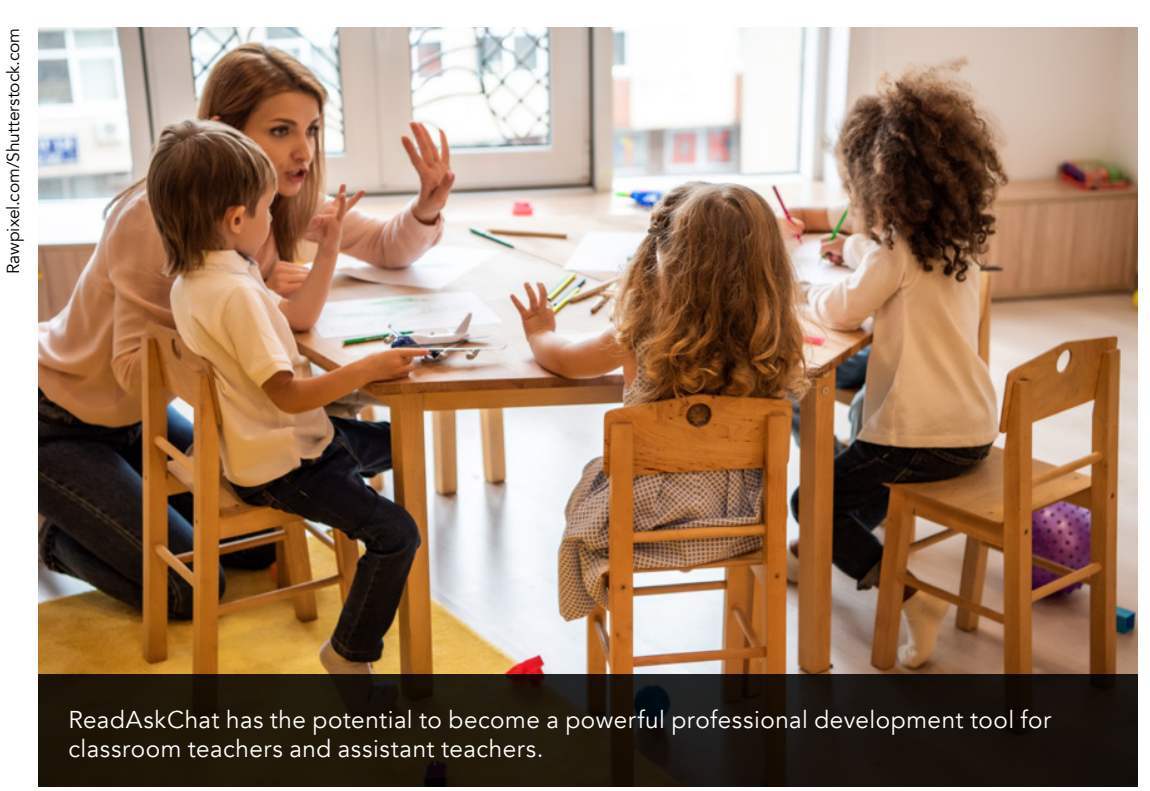

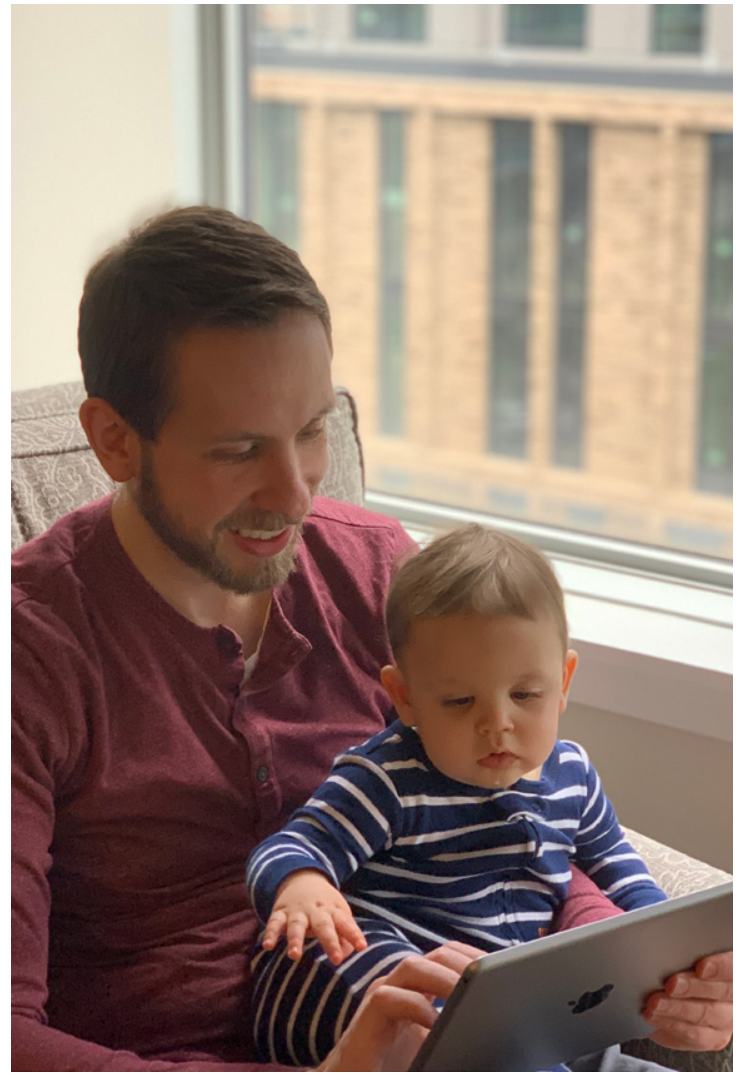

ReadAskChat embraces the definition of engagement as the degree to which parents
work with teachers as partners in their children's educational success.

ReadAskChat may also play a role in Special Education; supporting youn mothers who are still in education themselves; and in volunteer tutoring programs. It may also help to address so-called "summer slide," a documented phenomenon in which children who are not actively occupied during the long halle

There is no doubt that demand for this inexpensive, accessible, and effective learning tool is high and may have the potential to change the educational lives and expectations of many children, especially those from less privileged backgrounds.

Find ReadAskChat on iTunes App Store. https.//itunes.apple.com/us/ app/readaskchat-for-children-0-4/

Google Play: https:///play.google.com/ store/apps/details?id=com.readaskchat

For information on ReadAskChat's online adult-learning programs visit www.readaskchat.net

\section{Behind the Research

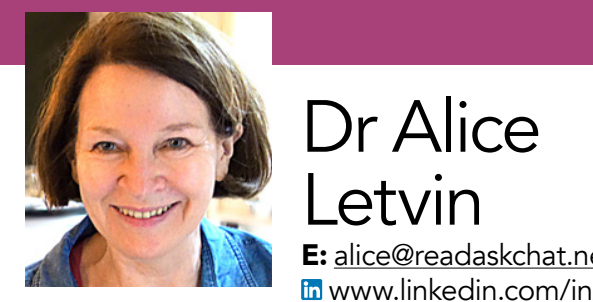 \\ T. Carolyn Saper MST \\ E: carolyn@readaskchat.net}

Đuww.twitter.com/readaskchat

References

- Hirsh-Pasek, K; Zosh, JM; Michnick, GR; Gray, JH; Robb, Apps: Lessons From the Science of Learning." Psychological Science in the Public Interest May 2015. Vol. 16, No.1, pp. 3-34.

r, L; Lowrance, A. "The Effects Children." Early Childhood Education Journal, December 2004, Vol 32, No 3.

-Mayer, SE; Kalii, A; Oreopoulos, P; Gallegos, S. "Using "Behavioral Insights to Increase Parental Engagement: Published online before print April 5 , 2018, http: // pher.org/papers/w21602. Human Resources Fall 2019, vol. 54 no. $4900-925$

- Morgan, PL; Farkas, G; Hillemeier, MM; Maczuga, S. "Science Achievement Gaps Begin Very Early, Persist, and Are Largely Explained by Mod Fable Factors." February 23, 2016, doi: 10.3102/0013189 X16633182 January/February 2016 vol. 45 no. 118-35.

- Neuman, SB; Celano, D. "Access to Print in LowIncome and Middle-Income Communities: An Research Quarterly, Vol 36, No 1. (Jan/Feb. Meading 2001), pp. 8-26.

- Pew Research Center. https://www. pewresearch.org/ internet/fact-sheet/mobile/.

- Romeo, RR; Leonard, JA; Robinson, ST; West, MR 30-Million-Word Gap: Children's C C." Beyond the Is Associated With Language-Related Brain Function." Psychological Science. Vol. 29.5, pp. 700-710. Article first published online: February 14, 2018. Issue published: May 1, 2018. Available at https://pubmed.ncbinlm.nih.

Shonkoff, J.P. \& Phillips, D.A. (Eds.) From Neurons to Neighborhoods: The Science of Early Childhood - Vygotsky, L.S. Mind in Society: The Development of Higher Psychological Processes. Harvard University Press, 1978. (O

\section{ReadAskChat

\section{Research Objectives}

ReadAskChat increases family access to high-quality stories and empowers parents and caregivers to foster school readiness by engaging in what paediatricians call dialogic reading-back-and-
forth communication about stories they are reading together.

Detail

ReadAskChat, Ltd.

1755 E. 55th St., Suite 1003

W: https://readaskchat.net

Contact us at: info@readaskchat.net

Alice Letvin, PhD, and Carolyn Saper, MST, have been colleagues for 30+ years, uniting their expertise in preschool-postsecondary literary publishing and curricula; early literacy instruction and

assessment; teacher professional development; and parent-
engagement programming. They cofounded ReadAskChat in 2016.

Funding

ReadAskChat was launched through multiple investments from the s.Surdevelopment and dissemination of innovative and impactful

\section{Collaborators}

ReadAskChat placed as a finalist in the 2016 University of Chicago Promise Venture Studio named ReadAskChat as one of the top 50 early childhood social enterprises in the nation.

\section{Personal Response}

How does ReadAskChat support children and parents from

II ReadAskChat levels the playing field for families by making a high-quality children's library easily accessible through smart percent of $U$ K h households now own. Through its enjoyable and easy-to-use method of dialogic reading, and supported by embedded, developmentally leveled prompts, parents and other caregivers can initiate and extend back-and-forth conversations that literally build children's brains, foster vocabulary and knowledge attainment, and spur sociabrain development. 